Western University

Scholarship@Western

Aboriginal Policy Research Consortium International (APRCi)

2012

\title{
Knowledge of an Aboriginal language and school outcomes for children and adults
}

Anne Guevremont

Dafna E. Kohen

Follow this and additional works at: https://ir.lib.uwo.ca/aprci

Part of the Bilingual, Multilingual, and Multicultural Education Commons

Citation of this paper:

Guevremont, Anne and Kohen, Dafna E., "Knowledge of an Aboriginal language and school outcomes for children and adults" (2012). Aboriginal Policy Research Consortium International (APRCi). 276.

https://ir.lib.uwo.ca/aprci/276 
This article was downloaded by: [University of Western Ontario]

On: 01 December 2012, At: 07:32

Publisher: Routledge

Informa Ltd Registered in England and Wales Registered Number: 1072954 Registered

office: Mortimer House, 37-41 Mortimer Street, London W1T 3J H, UK

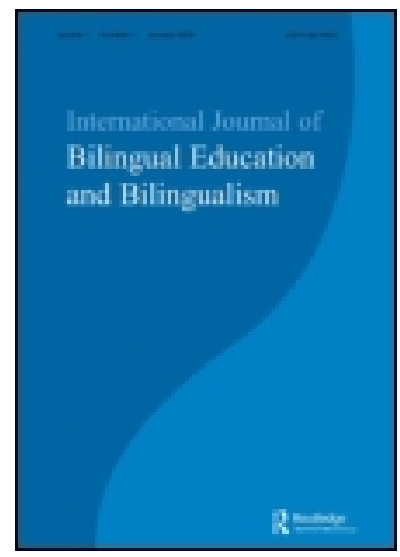

\title{
International J ournal of Bilingual Education and Bilingualism
}

Publication details, including instructions for authors and subscription information:

http:// www.tandfonline.com/loi/ rbeb20

\section{Knowledge of an Aboriginal language and school outcomes for children and adults}

\author{
Anne Guèvremont ${ }^{a} \&$ Dafna E. Kohen ${ }^{a b}$ \\ a Health Analysis Division, Statistics Canada, Ottawa, ON, Canada \\ ${ }^{b}$ Department of Epidemiology and Community Medicine, \\ University of Ottawa, Ottawa, ON, Canada \\ Version of record first published: $17 \mathrm{~J}$ un 2011.
}

To cite this article: Anne Guèvremont \& Dafna E. Kohen (2012): Knowledge of an Aboriginal language and school outcomes for children and adults, International J ournal of Bilingual Education and Bilingualism, 15:1, 1-27

To link to this article: http:// dx.doi.org/ 10.1080/ 13670050.2011.581268

\section{PLEASE SCROLL DOWN FOR ARTICLE}

Full terms and conditions of use: http://www.tandfonline.com/page/terms-andconditions

This article may be used for research, teaching, and private study purposes. Any substantial or systematic reproduction, redistribution, reselling, loan, sub-licensing, systematic supply, or distribution in any form to anyone is expressly forbidden.

The publisher does not give any warranty express or implied or make any representation that the contents will be complete or accurate or up to date. The accuracy of any instructions, formulae, and drug doses should be independently verified with primary sources. The publisher shall not be liable for any loss, actions, claims, proceedings, demand, or costs or damages whatsoever or howsoever caused arising directly or indirectly in connection with or arising out of the use of this material. 


\title{
Knowledge of an Aboriginal language and school outcomes for children and adults
}

\author{
Anne Guèvremont ${ }^{\mathrm{a}}$ and Dafna E. Kohen ${ }^{\mathrm{a}, \mathrm{b} *}$ \\ ${ }^{a}$ Health Analysis Division, Statistics Canada, Ottawa, ON, Canada $;{ }^{b}$ Department of \\ Epidemiology and Community Medicine, University of Ottawa, Ottawa, ON, Canada
}

(Received 9 August 2010; final version received 12 April 2011)

\begin{abstract}
This study uses data from the child and adult components of the 2001 Canadian Aboriginal Peoples Survey to examine what factors are related to speaking an Aboriginal language and how speaking an Aboriginal language is related to school outcomes. Even after controlling for child and family factors (age, sex, health status, household income, number of people living in the household, and living in an urban or rural area), speaking an Aboriginal language was associated with positive school outcomes for young children aged 6-14 years old if they learned the language in school, but a lower likelihood of having completed high school for 20-34-year olds. Possible reasons for this difference between child and adult results are discussed.
\end{abstract}

Keywords: indigenous; Aboriginal; language; children; adults; high school graduation; post-secondary graduation; parent-rated school performance

In Canada, Aboriginal children and youth's educational outcomes are significantly worse than the outcomes for non-Aboriginal students. In 2006, 34\% of Aboriginal peoples had less than a high school education compared to only $15 \%$ nationally (Statistics Canada 2009). At the elementary school level, the percentage of Grade 4 Aboriginal students in British Columbia who were 'Not Meeting Expectations' for reading in 2009 was $13 \%$ greater for Aboriginal students compared to nonAboriginal students (28\% vs. $15 \%)$, and at Grade 7 the rate was $15 \%$ higher $(32 \%$ vs. 17\%; British Columbia Ministry of Education 2010). Reports on Aboriginal education in Canada have repeatedly stressed the importance of promoting Aboriginal language and culture in the school curriculum (e.g. Hawthorn et al. 1967; Royal Commission on Aboriginal Peoples 1996; Task Force on Aboriginal Languages and Cultures 2005). The Canadian Council on Learning $(2008,5)$ states that, 'Creating a climate in which Aboriginal students feel welcomed and valued can help overcome feelings of alienation toward schooling'. These recommendations suggest that instruction of an Aboriginal language in school could improve Aboriginal students' school outcomes.

Aboriginal language is an important part of cultural identity and particularly important to the culture of Aboriginal peoples. It is 'not only a means of communication, but a link which connects people with their past and grounds their social, emotional, and spiritual vitality' (Norris 1998, 8). The Royal Commission on

*Corresponding author. Email: dafna.kohen@statcan.gc.ca 
Aboriginal Peoples recognises that the revitalisation of traditional languages is a key component in the creation of healthy individuals and communities (Royal Commission on Aboriginal Peoples 1996). The percentage of people able to carry on a conversation in an Aboriginal language varies by Aboriginal group. According to the Census of Canada (Statistics Canada 2009), 69\% of Inuit were able to converse in an Aboriginal language (in 2006) compared to $51 \%$ of First Nations people living on reserve, $12 \%$ of First Nations people living off reserve, and $4 \%$ of Métis. However, the use of Aboriginal languages is on the decline for all groups (Burnaby and Beaujot 1986). The percentage of First Nations people living off reserve who were able to converse in an Aboriginal language decreased from 20\% in 1996 to $12 \%$ in 2006 (Statistics Canada 1998, 2009). On reserve, knowledge of an Aboriginal language also decreased from $56 \%$ in 1996 to $51 \%$ in 2006 . For Métis people, $9 \%$ were able to converse in an Aboriginal language in 1996 compared to only 4\% in 2006. As well, the percentage of Inuit able to converse in an Aboriginal language also decreased from $72 \%$ in 1996 to $69 \%$ in 2006 . The rapidity with which the use of these languages is decreasing places Aboriginal languages in a unique category compared to other minority languages as their loss implies the extinction of those languages (Burnaby and Beaujot 1986).

Until about the 1950s, schooling for Aboriginal children was mostly contracted to Christian groups; a later policy moved to integrate all Aboriginal children into provincial schools, or in remote areas, to establish federally run schools (Burnaby 2008). Often the educational policies in these schools forced Aboriginal children to speak English or French in school, even to the extent of severe physical punishment for speaking an Aboriginal language (Burnaby 2008). Since the 1960s, Aboriginal languages have been taught in some Aboriginal and provincial schools as subjects of instruction (Assembly of First Nations 1990; Kirkness and Sheena 1992), although the distribution and number of Aboriginal language programs in Canada is unknown and there is much variability by Aboriginal group. Different Aboriginal groups in Canada (Inuit, First Nation on and off reserve, and Métis) tend to be served by different types of schools. Off-reserve First Nations children attend provincial schools that largely have policies in place for teaching Aboriginal children but not for teaching Aboriginal language per se. First Nations children on reserve go to band-controlled schools or have tuition agreements with provincial schools that may or may not support high quality Aboriginal language teaching. While the Inuit are largely concentrated in Nunavut, Nunatsiavut, and the North West Territories, all of these areas have policies concerning Inuktitut as a subject or medium of instruction as do children in the James Bay Cree region. In addition, many leave their home communities to attend high school. For example, in 1975, the Katavik School Board was created in Nunavik in northern Quebec providing an Aboriginal language as the language of instruction in the first three years of school (Kativik School Board 2010). The Mohawk on the Kahnawake reserve opened the first First Nations language immersion program in Canada in 1979, serving children from preschool to Grade 6 (Ball 2007). Language programmes have also been developed in First Nations communities in British Columbia. In 2009/2010, 8\% of band-operated schools in British Columbia had First Nations language immersion programs (First Nations Schools Association 2010). The Aboriginal Peoples Survey found that in 2001, 36\% of children under 15 who could understand or speak an Aboriginal language received some help from their schoolteachers in learning their Aboriginal language (Statistics Canada 2003a). This rate was highest in Northern Canada, 
where over half $(55 \%)$ of children who could understand or speak an Aboriginal language received help from their teachers.

More recently, the Government of Canada has recognised the importance of Aboriginal languages and cultures. The 2002 Speech from the Throne (a speech that officially opens every new session of parliament in Canada and sets out the broad goals and directions of the government and the initiatives it will undertake to accomplish those goals; Government of Canada 2010) made a commitment to help preserve, revitalise, and promote First Nations, Inuit and Métis languages and cultures (Government of Canada 2002). As a result of this commitment, Heritage Canada (a department of the Canadian Federal Government) established an Aboriginal Languages and Cultures Centre as well as a Task Force on Aboriginal Languages and Cultures (2005). As well, many provincial governments have made a commitment to Aboriginal languages. In February 1997, Alberta, British Columbia, Manitoba, Saskatchewan, the Northwest Territories, and the Yukon Territory signed a memorandum agreeing to pool resources to develop an Aboriginal Languages Framework (Manitoba Education, Citizenship and Youth 2007a). The provinces of Manitoba and Saskatchewan have produced documents focusing on the education policy of Aboriginal students; both documents include a focus on Aboriginal language curriculum (Saskatchewan Education, Training and Employment 2003; Manitoba Education, Citizenship and Youth 2007b).

\section{Aboriginal immersion programs in Canada}

Although several Aboriginal immersion programs exist in Canada, research on these programs is limited. In Nunavik in Northern Quebec, research has shown that Inuit language programs had some positive impacts on children's academic outcomes and self-esteem. Louis and Taylor (2001) demonstrated that a strong foundation in an Aboriginal language in the last year of an elementary school Aboriginal language education program was the best predictor of success in the subsequent year of education in English or French. Wright and Taylor (1995) found that kindergarten instruction in an Aboriginal language was associated with increases in personal selfesteem at the end of the year, whereas kindergarten instruction in English or French had no such benefit for Aboriginal children.

As stated above, the Mohawk on the Kahnawake reserve started a First Nations language immersion program in 1979. This program has had a number of positive effects for students (Task Force on Aboriginal Languages and Cultures 2005). More than $85 \%$ of the immersion students passed either the Grade 10 or Grade 12 literacy test or courses (in English or French); however, the percentage of non-immersion students who passed similar tests was not reported.

Bell et al. (2004) and Fulford et al. (2007) conducted case studies of 20 successful Aboriginal schools across Canada. The schools were selected based on quantitative data on outcomes such as graduation rates, satisfaction surveys, and provincial examination results, as well as a nomination process from knowledgeable informants such as the Departments of Education, school districts, and First Nations groups. Language and cultural programs were present in every school profiled, and each school offered instruction in the Aboriginal language of the community (Phillips and Raham 2008). Although English was the dominant language used in the majority of schools, most used the local language to exchange greetings, for ceremonial purposes, and to supplement instruction. These case studies suggest that language and cultural 
programs may be an important factor contributing to successful Aboriginal schools. Other common factors at these schools included leadership effectiveness and a school climate of trust and high standards.

However, not all studies of Aboriginal immersion programs have yielded positive results. The Cree School Board in Eastern Quebec instituted the Cree Language of Instruction Program in 1991, where Cree was the primary language of instruction from kindergarten to Grade 2/3, followed by instruction in English or French. Although several reports of this program were positive (Stiles 1997; Bell et al. 2004), others have been critical. The language program was assessed as part of an Educational Review conducted in 2007/2008 (Cree School Board 2008). Canadian Achievement Test results (a standardised test with criterion-based norms) from 2003/ 2004 to 2006/2007 showed that less than half of students were reaching expected competencies in reading, language, and mathematics in Grades 6 and 9 - percentages ranged from $16 \%$ meeting expected competencies on the Grade 6 French test to $47 \%$ on the Grade 9 English test. These negative results are largely based on standardised test outcomes that may not be the most appropriate assessments for Aboriginal children. Quantitative self-reported outcomes by parents, teachers, and principals suggested more positive outcomes including significant decreases in the drop out rate (Bell et al. 2004; Feurer 1993; Stiles 1997). Based on these test results as well as interviews with teachers and students, the authors concluded that the program, 'has done a poor job in teaching Cree as a language, and has completely failed to provide a language of instruction for curricular learning. An entire generation of students has passed through the current regime and they are failing in record numbers' (Cree School Board 2008, 97). The authors report a range of reasons for the difficulties of the program including under-qualified teachers and a lack of programming for the transition from instruction in Cree to instruction in English or French. The school board review also describes many other challenges faced by the schools of the Cree School Board, including poor student attendance, high teacher absenteeism with unqualified substitution, inadequate classroom facilities, problems with teacher quality, and inadequate instructional materials. Separating the effects of the language program on student outcomes from the other difficulties faced by the school board is difficult. In addition, there was no comparison group included in the study, for example, a group of Cree students who did not receive instruction in the Cree language.

\section{International Aboriginal immersion programs}

Internationally, there are examples of language programs in indigenous communities that have shown positive results including positive associations with academic outcomes. In New Zealand, Maori immersion programs in state-funded schools were established in the 1980s (Harrison 1998). High school students at Maori-medium schools (where Maori language made up at least 12\% of teaching and learning) were more likely to meet both the literacy and numeracy requirements of the National Certificate of Educational Achievement (83\%) than Maori candidates in other schools (66\%; Ministry of Education 2008). In New Zealand for the same year, $82 \%$ of non-Maori students met both the literacy and numeracy requirements. Thus, Maori students educated in Maori immersion programs in state-funded schools had similar rates of literacy and numeracy achievement as non-Maori students and fared better than Maori students in non-immersion programs. Moreover, Maori students 
in immersion schools had lower suspension rates compared to Maori students in non-immersion schools ( $6 \%$ vs. $17 \%$ of students).

The Navajo Nation in the southwestern United States offers Navajo immersion programs to its students. The immersion program began in 1986 and currently offers full immersion in kindergarten and Grade 1, which is decreased by $10 \%$ each year from 90\% Navajo in Grade 2 to 50\% in Grade 6 (Romero-Little and McCarty 2006). In 2004, third grade immersion students were performing similar to or better than non-immersion third graders on standardised Math and English assessments. For Math, $68 \%$ of Navajo immersion students were meeting or exceeding state standards on Arizona's Instrument to Measure Standards (AIMS) compared to 15\% of Navajo students in the mainstream English program (Romero-Little and McCarty 2006). Immersion students also performed better on English writing with 55\% meeting or exceeding state standards compared to $15 \%$ of mainstream English students. There was no difference between immersion and English students for English reading, 36\% of immersion students meeting of exceeding state standards compared to $37 \%$ of mainstream English students.

Overall, Aboriginal immersion programs appear to be associated with positive school outcomes both in Canada and internationally, although the majority of research has been conducted with individual programs and relatively small groups of students. As well, few studies have been able to control for child and family demographic factors such as family income.

\section{Method}

\section{Study overview}

The current study expands on existing research examining the relationship between Aboriginal language instruction and school outcomes. An advantage of the present study is the use of Canadian national data including First Nations on and off reserve as well as Inuit and including a wider range of children and adults focusing on two groups, children aged 6-14 and adults aged 20-34. Since preliminary analyses reported few Métis speaking an Aboriginal language $(6 \%$ of adults and 3\% of children in our sample), this study focuses on Inuit and First Nations peoples.

The context for learning an Aboriginal language is different for Inuit children and for First Nations children living on and off reserve as they are served by different types of school (Kirkness and Sheena 1992). For Inuit, the majority of adults speak the language, and children are more likely to arrive at school speaking Inuktitut as their first language (Statistics Canada 2009; Tait, Cloutier, and Bougie 2010). However, the challenges for children speaking an Aboriginal language when starting school differ from the challenges for children who already speak English or French (Wright, Taylor, and Macarthur 2000). Research suggests that children do better when preschool, kindergarten, and primary school are provided in the same language as they have been learning at home (Wright, Taylor, and Macarthur 2000). In contrast to Inuit children, although some First Nations children may start school speaking a language other than French or English, the majority of First Nations children do not speak an Aboriginal language at school entry (Statistics Canada 2009; Bougie, Tait, and Cloutier 2010). First Nations children are more likely than Inuit children to be learning an Aboriginal language as a second language when they learn it in school (Norris 2007). Furthermore, First Nations students living on 
reserve may have more opportunity to be exposed to First Nations language and culture compared to First Nations children living off reserve, as a higher percentage of people living on reserve speak an Aboriginal language (Statistics Canada 2009). For these reasons, learning an Aboriginal language in school may have more positive benefits for Inuit children and on-reserve First Nations children who are more likely to speak an Aboriginal language when they start school.

Inclusion of both children and adults in the study is important for a number of reasons. Different outcomes are available for children and adults on the Aboriginal Peoples Survey. For children, parents answer questions about how well the child is doing in school, whether the child likes school, and whether the child has repeated a grade or been suspended or expelled from school. For adults, the outcomes of high school completion and post-secondary education completion are both included in the study. Also, although assessment of child outcomes provides a more recent assessment of Canadian schools (data from 2001), the assessment of adult outcomes provides more information on the long-term outcomes of speaking an Aboriginal language and of learning it in school (i.e. Is learning an Aboriginal language at school associated with adult educational outcomes 10-20 years after learning the language in school?).

This study uses both the child and adult components of the 2001 Aboriginal Peoples Survey (APS; Statistics Canada 2003b) to examine the following questions:

(1) What are the characteristics of a Canadian population-based cohort of children and adults who report speaking an Aboriginal language?

(2) Who helps children learn an Aboriginal language and where do adults use their Aboriginal language? Does this differ by Aboriginal group (First Nations on selected reserves, First Nations off reserve, and Inuit)?

(3) How is speaking an Aboriginal Language related to school outcomes for a cohort of children and a cohort of adults?

(4) What is the impact on children's and adults' school outcomes (child outcomes: doing well in school, liking school, having repeated a grade, and having been suspended or expelled; adult outcomes: completed high school, completed post-secondary education) of being taught an Aboriginal language at school as compared to instruction outside of school?

\section{Data source}

This study uses the child and adult components of the 2001 APS (Statistics Canada 2003b). The APS provides data on the social and economic conditions of Aboriginal peoples in Canada. Its specific purpose was to identify the needs of Inuit, First Nations (on and off reserve), and Métis peoples focusing on issues such as health, schooling, and language. The survey was designed and implemented in partnership with National Aboriginal Organisations including the Assembly of First Nations, Métis National Council, Inuit Tapiriit Kanatami, Congress of Aboriginal Peoples, National Association of Friendship Centres, and the Native Women's Association (Statistics Canada 2003b). The APS is a post-censal survey, meaning that respondents were selected based upon their self-identification in the 2001 Census of Canada.

Both the Adult and Child Components of the APS were used in this study. The adult component was completed by adults (self-reported) aged 15 years and older 
and was limited to respondents aged 20-34 years for this study. This age group was selected as one of our outcomes of interest was high school completion, so we selected a group that was likely to have finished high school, but finished high school relatively recently. The child component was given to children aged $0-14$ years and was limited to 6-14-year olds in the present study. The sample included children aged six and older because of the focus on school outcomes that were only asked of this age group. Interviews for the children's questionnaire were conducted with the 'person most knowledgeable' (PMK) about the child. In $82 \%$ of cases, the PMK was the birth parent (mother or father). In other instances, the PMK was a grandparent $(6 \%)$, or an aunt or uncle $(3 \%)$. For simplicity, the PMK will be referred to as 'parent' in this study. In most cases, the interviews were conducted face-to-face using paper and pencil questionnaires.

\section{Definitions of variables \\ Aboriginal identity group}

Respondents were asked, 'Is your child/Are you an Aboriginal person, that is, North American Indian, Métis, or Inuit?' Both the Inuit sample in the APS and the First Nations off-reserve sample are representative of those groups nationally. However, due to cost restraints, the APS sampling strategy for the First Nations on-reserve population only focused on the larger reserves in each province (Statistics Canada 2003b). As a result, the information collected for the First Nations on-reserve sample was not designed to be representative of the entire on-reserve population ${ }^{1}$ (see Appendix 1 for a list of all communities included in the survey). About one-third of the on-reserve identity population is represented for British Columbia, New Brunswick, Ontario, and Quebec; about half to three-quarters of the on-reserve population is represented for the other provinces. This should be taken into consideration when interpreting results for the First Nations on-reserve population.

\section{Knowledge of an Aboriginal language}

The adult component of the 2001 APS asked respondents if they could speak or understand an Aboriginal language. The child component asked parents if their child could speak or understand an Aboriginal language. The survey also asked respondents how well they (or their child) spoke their primary Aboriginal language. For this study, respondents who spoke their language with effort, relatively well, or very well were considered as speaking an Aboriginal language. Respondents who spoke only a few words, or who responded that they did not speak or understand an Aboriginal language were considered as not speaking an Aboriginal language. A similar measure (ability to converse in an Aboriginal language) has been used by the Census of Canada (Statistics Canada 2009).

\section{Taught an Aboriginal language in school}

In the child component, parents were asked who helps the child in learning his or her Aboriginal language. Children with parents who responded that his or her schoolteachers helped the child learn the language were categorised as being taught an Aboriginal language in school. This question was a multiple-response question, 
meaning that parents could answer that more than one person or group of people helped their child learn an Aboriginal language. For this study, parents who responded 'schoolteachers' only and those who responded 'schoolteachers' in conjunction with other individuals were included in the group of children categorised as being taught an Aboriginal language in school.

In the adult component, respondents were asked retrospectively if any of their teachers or teachers' aides taught them in an Aboriginal language, and if they were taught an Aboriginal language while attending elementary or high school. If the respondent answered yes to either of these questions then they were categorised as being taught an Aboriginal language in school. Each question was included in order to match the broader definition of being taught an Aboriginal language in school used for the child component. The majority of respondents (93\% of Inuit, 76\% of onreserve First Nations, and $65 \%$ of off-reserve First Nations) who were categorised as being taught an Aboriginal language responded yes to both questions. ${ }^{2}$

Success in the formal education system: outcomes from the child component

Did well in school. Students whose parents said they did well or very well in school were categorised as 'did well in school' compared to students whose parents said they did average, poorly, or very poorly in school. Approximately 69\% of Inuit children were categorised as doing well in school, along with $65 \%$ of First Nations children on selected reserves and $64 \%$ of First Nations children off reserve.

Looked forward to going to school. Students whose parents said they looked forward to going to school almost always were categorised as 'looked forward to going to school' compared to students whose parents said they looked forward to going to school sometimes, rarely, or almost never. About $79 \%$ of Inuit children and $80 \%$ each of First Nations children on selected reserves and off reserve looked forward to going to school.

Repeated a grade. ${ }^{3}$ Children whose parents said their child had repeated a grade were compared to children whose parents said their child had never repeated a grade. Parents reported that $19 \%$ of Inuit children, $24 \%$ of First Nations children on selected reserves, and $14 \%$ of First Nations children off reserve had repeated a grade.

Suspended or expelled from school. Children whose parents said their child had been suspended or expelled from school were compared to children whose parents said their child had never been suspended or expelled from school. Approximately $13 \%$ of Inuit children, $15 \%$ of $\mathrm{FN}$ children on selected reserves, and $16 \%$ of $\mathrm{FN}$ children off reserve had been suspended or expelled from school.

\section{Success in the formal education system: adult component}

Completed high school. Completing high school included both graduating from high school and successfully completing a high school equivalency program (as reported by the respondent). About $34 \%$ of Inuit, $42 \%$ of First Nations living on selected reserves, and $66 \%$ of First Nations living off reserve had completed high school. 
Completed post-secondary education (PSE). For adults who had graduated from high school, PSE completion included a certificate, diploma, or degree at a trade school, non-university institution (community college, CEGEP, technical institute), or university (as reported by the respondent). Of adults who had completed high school, about $33 \%$ of Inuit, $26 \%$ of First Nations living on selected reserve, and $34 \%$ of First Nations living off reserve had completed PSE.

\section{Analysis}

Descriptive analyses (percentages) were used to describe the characteristics of Aboriginal language speakers, who helps children learn an Aboriginal language, and where adults use their Aboriginal language. Differences between the characteristics of non-language speakers and language speakers were assessed with $t$-tests. Multiple logistic regression was used to examine the association of knowledge of an Aboriginal language, having been taught an Aboriginal language in school, and school outcomes. All models controlled for gender (male, female), age (6-8, 9-11, 12-14), health status (excellent/very good vs. good/fair/poor), household income (lowest, middle, high computed for each group, Inuit, First Nations on and First Nations off reserve separately), number of people living in the household $(2-4,5-6$, $7+)$, and living in an urban or rural area. These socio-demographic variables are associated both with speaking an Aboriginal language and with school outcomes (Bougie 2009; Thomas 2009). For the descriptive analyses, certain categories were grouped together based on sample size considerations. Analyses were all weighted in order to be nationally representative, except for First Nations on selected reserves that were weighted to represent the sampled reserves. ${ }^{4}$ The bootstrap method was used to account for the complex sampling design used by the survey (Rao, $\mathrm{Wu}$, and Yue 1992; Rust and Rao 1996).

\section{Results \\ Who speaks an Aboriginal language?}

In our sample of children aged 6-14, there was much variability in speaking an Aboriginal language between Aboriginal groups. The majority of Inuit $(63 \%)$ but fewer First Nations children on selected reserves (38\%), and even fewer First Nations children off reserve (11\%) spoke an Aboriginal language. Among adults aged $20-34$, the majority of Inuit adults $(72 \%)$, as well as First Nations adults on selected reserves $(61 \%)$ spoke an Aboriginal language, with only a minority of First Nations adults living off reserve (18\%) speaking an Aboriginal language. The trends across groups are consistent with results from the Census of Canada (Statistics Canada 2009).

Compared to Inuit children who did not speak an Aboriginal language, Inuit children who spoke an Aboriginal language were more likely to be in good, fair, or poor health; be living in large households (seven or more people); and to have parents who thought that learning an Aboriginal language was very important $(91 \%$ vs. $40 \%$; Table 1). Compared to First Nations children living on reserve who did not speak an Aboriginal language, First Nations children living on selected reserves who spoke an Aboriginal language were more likely to be living in large households, more likely to be in the highest income tertile, and more likely to have parents who thought 
Table 1. Child sample characteristics (percentages).

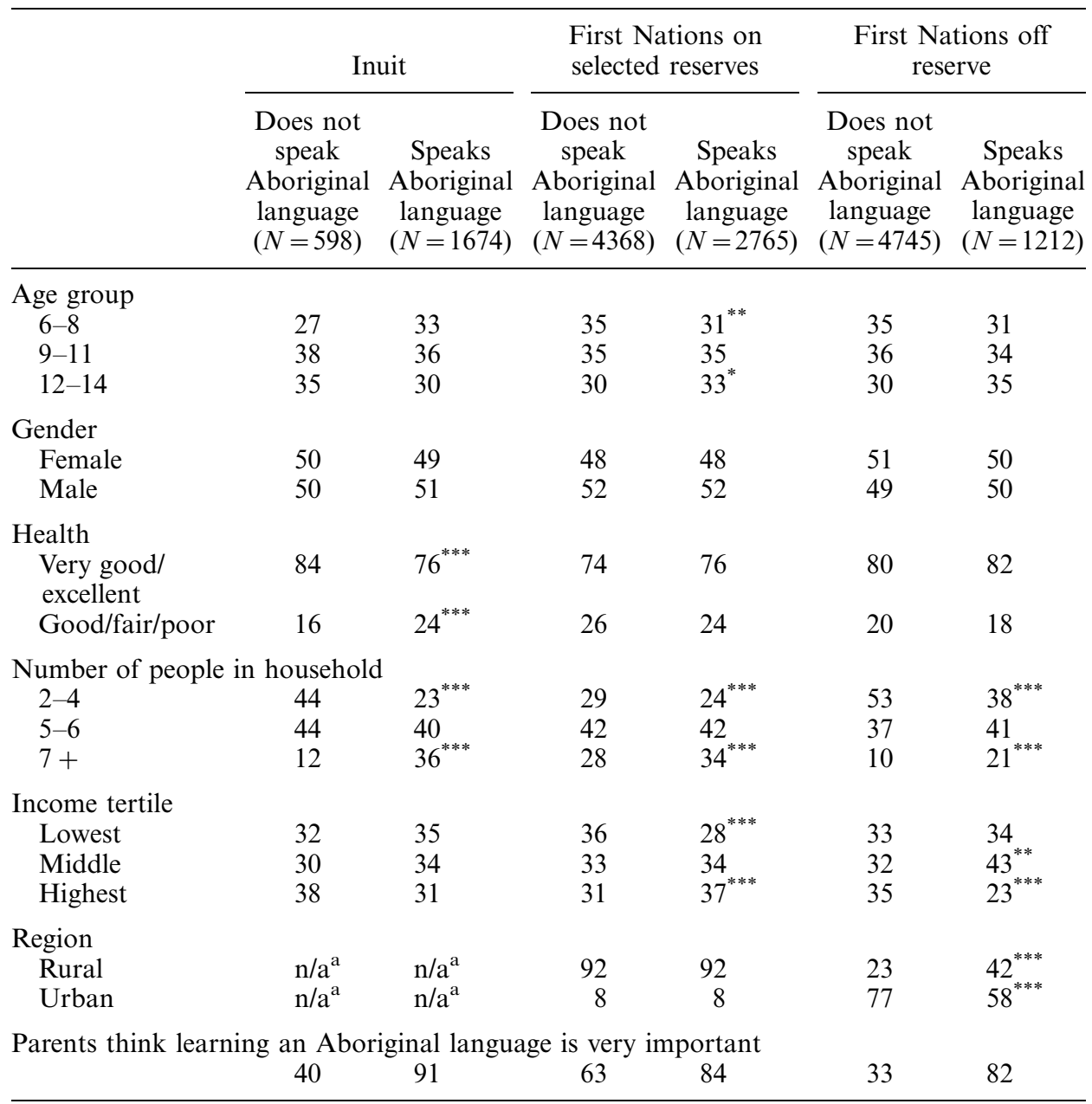

Source: 2001 Aboriginal Peoples Survey.

${ }^{*} p<0.05$, compared to children in the same identity group who do not speak an Aboriginal language. ${ }^{* *} p<0.01$, compared to children in the same identity group who do not speak an Aboriginal language. $* * * p<0.001$, compared to children in the same identity group who do not speak an Aboriginal language. ${ }^{a}$ More than $80 \%$ of Inuit in this sample were categorised as living in the Arctic and therefore not categorised as living in either a rural or urban area.

Note: Results presented as row percentages available upon request.

that learning an Aboriginal language was very important. Compared to First Nations children living off reserve who did not speak and Aboriginal language, First Nations children living off reserve who spoke an Aboriginal language were less likely to be in the highest income tertile, more likely to be living in large households, to be living in rural areas, and to have parents who thought that learning an Aboriginal language was very important.

Compared to Inuit adults who did not speak an Aboriginal language, those who spoke an Aboriginal language were more likely to live in large households (7+ people; Table 2). Inuit adults who spoke and those who did and did not speak an 
Table 2. Adult sample characteristics (percentages).

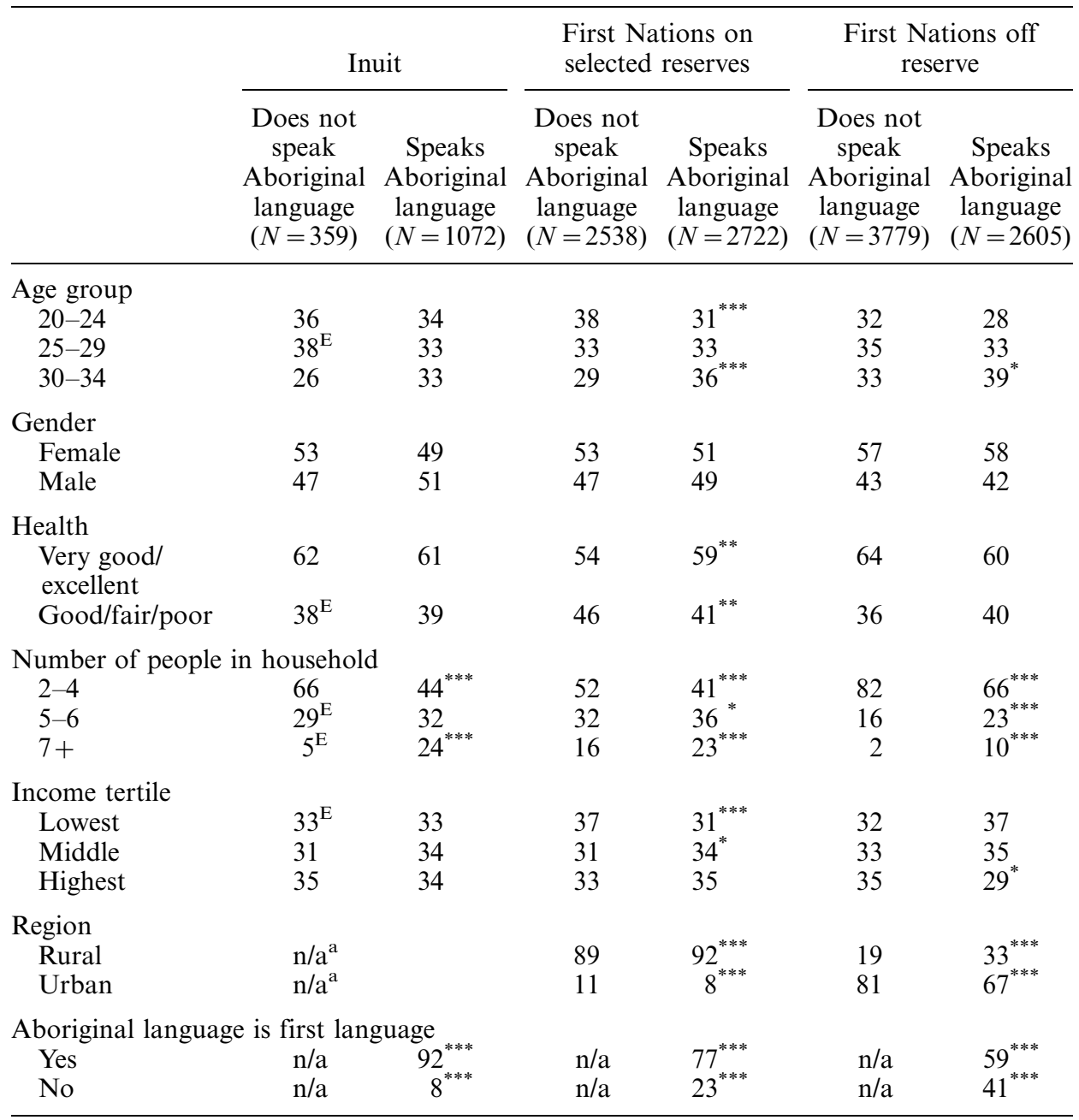

Source: 2001 Aboriginal Peoples Survey.

${ }^{*} p<0.05$, compared to adults in the same identity group who do not speak an Aboriginal language.

${ }^{* *} p<0.01$, compared to adults in the same identity group who do not speak an Aboriginal language.

${ }^{* * *} p<0.001$, compared to adults in the same identity group who do not speak an Aboriginal language.

${ }^{a}$ More than $80 \%$ of Inuit in this sample were categorised as living in the Arctic and therefore not categorised as living in either a rural or urban area.

${ }^{\mathrm{E}}$ Due to high coefficients of variation and low sample size for this group, the estimate should be interpreted with caution.

Aboriginal language were of similar age, gender, income group, and health status. Compared to First Nations on selected reserves who did not speak an Aboriginal language, adults who spoke an Aboriginal language were more likely to be older, living in large households (with seven or more people), in excellent or very good health, and living in a rural area. First Nations living off reserve who spoke an Aboriginal language were more likely to be living in a rural area, and more likely to live in large households $(7+$ people), than First Nations living off reserve who did not speak an Aboriginal language. 


\section{Who helped children learn an Aboriginal language?}

Parents were the most likely to help Aboriginal children learn an Aboriginal language. Of children who spoke an Aboriginal language, $87 \%$ of Inuit parents helped their child learn the language, compared to $80 \%$ of First Nations parents on selected reserves and $69 \%$ of First Nations parents off reserve. A high percentage of schoolteachers also helped children learn an Aboriginal language, particularly for Inuit children. Schoolteachers were more likely to help Inuit children who spoke an Aboriginal language learn their language (67\%) compared to 58\% of First Nations children on selected reserves and $46 \%$ of First Nations children off reserve. However, grandparents, aunts/uncles, and community elders were more likely to help First Nations children (both on selected reserves and off reserve) learn their Aboriginal language compared to Inuit children. Other relatives, friends, and the community were equally reported for all three groups.

\section{Where do adults use their Aboriginal language?}

Inuit adults who spoke an Aboriginal language were more likely to have an Aboriginal language as their first language (92\%) compared to First Nations adults on selected reserves $(77 \%)$ and First Nations adults off reserve $(59 \%)$ who spoke an Aboriginal language (Table 2). Inuit were more likely to use their Aboriginal language at home, work, school, and other places compared to First Nations living on selected reserves; both Aboriginal groups were more likely to use their language at these places compared to First Nations living off reserve. Almost three-quarters of Inuit adults used their Aboriginal language at home, compared to 57\% of First Nations on selected reserves and $36 \%$ of First Nations living off reserve. Almost half (48\%) of Inuit adults who spoke an Aboriginal language also used the language at work, compared to $38 \%$ of First Nations living on selected reserves, and $16 \%$ of First Nations living off reserve. Lastly, more Inuit used their language in places other than home, school, or work (67\%) compared to First Nations living on selected reserves (49\%), and First Nations living off reserve (29\%).

\section{How does knowledge of an Aboriginal language relate to children's school outcomes?}

Logistic regression was used to examine how knowledge of an Aboriginal language was associated with children's school outcomes. Children who did not speak an Aboriginal language were compared to two different groups of children: (1) children who spoke an Aboriginal language but did not receive help learning their language from their schoolteachers and (2) children who spoke an Aboriginal language and received help learning their language from their schoolteachers.

Among Inuit children, children who spoke an Aboriginal language and were helped by their schoolteachers were more likely to be doing well in school as compared to Inuit children who did not speak an Aboriginal language (Table 3 and Figure 1). Inuit children who spoke an Aboriginal language but did not receive help learning it at school were also more likely to be doing well at school compared to those children who did not speak an Aboriginal language but this difference was not statistically significant. The two groups of Inuit children who spoke an Aboriginal language (namely those who were and were not helped to learn the language by their schoolteachers) did not significantly differ from children who did not speak an 
Table 3. Odds ratios and confidence intervals predicting children's outcomes.

\begin{tabular}{|c|c|c|c|c|c|c|c|}
\hline \multirow[b]{2}{*}{ Outcome } & & \multicolumn{2}{|r|}{ Inuit } & \multicolumn{2}{|c|}{$\begin{array}{l}\text { First Nations on } \\
\text { selected reserves }\end{array}$} & \multicolumn{2}{|c|}{$\begin{array}{c}\text { First Nations off } \\
\text { reserve }\end{array}$} \\
\hline & & OR & $95 \% \mathrm{CI}$ & OR & $95 \% \mathrm{CI}$ & OR & $95 \% \mathrm{CI}$ \\
\hline \multirow[t]{4}{*}{ Doing well in school } & $\begin{array}{l}\text { Does not speak an Aboriginal Language } \\
\text { Speaks an Aboriginal Language }\end{array}$ & 1.00 & & 1.00 & & 1.00 & \\
\hline & Schoolteachers do not help & 1.41 & $(0.97-2.05)$ & 1.40 & $(1.18-1.66)$ & 0.91 & $(0.62-1.35)$ \\
\hline & Schoolteachers help & 1.62 & $(1.17-2.24)$ & 1.44 & $(1.16-1.79)$ & 1.09 & $(0.62-1.92)$ \\
\hline & $N$ & 2180 & & 6241 & & 5684 & \\
\hline \multirow[t]{4}{*}{ Looks forward to going to school } & $\begin{array}{l}\text { Does not speak an Aboriginal Language } \\
\text { Speaks an Aboriginal Language }\end{array}$ & 1.00 & & 1.00 & & 1.00 & \\
\hline & Schoolteachers do not help & 1.06 & $(0.71-1.58)$ & 0.79 & $(0.63-0.98)$ & 0.54 & $(0.34-0.85)$ \\
\hline & Schoolteachers help & 0.97 & $(0.70-1.35)$ & 1.19 & $(0.95-1.49)$ & 1.10 & $(0.63-1.93)$ \\
\hline & $N$ & 2191 & & 6247 & & 5691 & \\
\hline \multirow[t]{4}{*}{ Repeated a grade } & $\begin{array}{l}\text { Does not speak an Aboriginal Language } \\
\text { Speaks an Aboriginal Language }\end{array}$ & 1.00 & & 1.00 & & 1.00 & \\
\hline & Schoolteachers do not help & 1.19 & $(0.76-1.85)$ & 1.08 & $(0.87-1.35)$ & 0.99 & $(0.62-1.59)$ \\
\hline & Schoolteachers help & 1.15 & $(0.79-1.67)$ & 0.95 & $(0.79-1.14)$ & 1.30 & $(0.80-2.12)$ \\
\hline & $N$ & 2199 & & 6237 & & 5691 & \\
\hline \multirow[t]{4}{*}{ Suspended or expelled from school } & $\begin{array}{l}\text { Does not speak an Aboriginal Language } \\
\text { Speaks an Aboriginal Language }\end{array}$ & 1.00 & & 1.00 & & 1.00 & \\
\hline & Schoolteachers do not help & 0.64 & $(0.37-1.12)$ & 0.96 & $(0.74-1.25)$ & 1.21 & $(0.64-2.27)$ \\
\hline & Schoolteachers help & 0.75 & $(0.47-1.20)$ & 0.95 & $(0.75-1.19)$ & 1.44 & $(0.81-2.54)$ \\
\hline & $N$ & 2218 & & 6256 & & 5707 & \\
\hline
\end{tabular}

Source: 2001 Aboriginal Peoples Survey.

Results significant at $p<0.05 \%$ are in bold. All models control for age, gender, health status, income, and number of people in the household. Models for First Nations also control for living in an urban or rural area. 


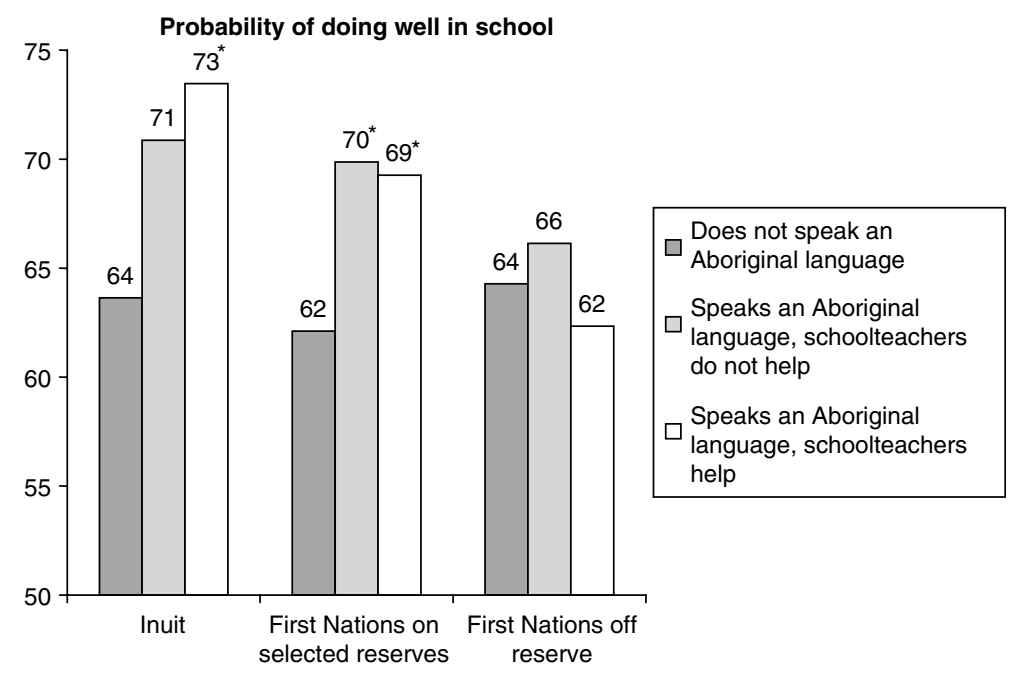

Figure 1. Impact of speaking an Aboriginal language and help received by schoolteachers on the probability of doing well in school.

Note: Values in figure control for gender, age, health, number of people in the household, income, and urban/rural region.

${ }^{*} p<0.05$, compared to children in the same identity group who do not speak an Aboriginal language.

Aboriginal language in looking forward to going to school, repeating a grade, or having been suspended or expelled. However, there was a non-significant trend for Inuit Aboriginal language speaking children to be more likely to repeat a grade, and less likely to be suspended or expelled from school, regardless of whether or not they were helped to learn an Aboriginal language in school. These analyses controlled for gender, age, health status, household income, number of people living in the household, and living in an urban or rural area.

For First Nations children living on reserve, children who spoke an Aboriginal language, both those who were and were not helped to learn an Aboriginal language by their schoolteachers, were more likely to be doing well in school than First Nations children on reserve who did not speak an Aboriginal language. However, First Nations children on reserve who spoke an Aboriginal language but were not helped to learn the language by their schoolteachers were less likely to look forward to going to school than First Nations children on reserve who did not speak an Aboriginal language. Children who spoke an Aboriginal language, regardless of assistance in Aboriginal language in school, were no different from children who did not speak an Aboriginal language in terms of repeating a grade or to having been suspended or expelled.

Among First Nations children living off reserve, those who spoke an Aboriginal language but were not helped with the language by their schoolteachers were less likely to look forward to going to school compared to those who did not speak an Aboriginal language. The two groups of children who spoke an Aboriginal language (both those who were and were not helped with the language by their schoolteachers) did not differ from children who did not speak an Aboriginal language in doing well in school, having repeated a grade, or having been suspended or expelled. However, First Nations children living off reserve who spoke an Aboriginal language showed a 
trend to be more likely to be suspended or expelled from schools, regardless of being helped to learn the language at school or not.

\section{How does knowledge of an Aboriginal language relate to adult school outcomes?}

Inuit adults who spoke an Aboriginal language, both those who were and were not taught the language at school, were less likely to have completed high school (Table 4) than Inuit adults who did not speak an Aboriginal language. However, for Inuit who had successfully graduated from high school, speaking an Aboriginal language (whether learned in school or not) was not associated with the likelihood of completing post-secondary school. These associations were over and above child and family factors.

Similarly, for First Nations adults living on selected reserves, those who spoke an Aboriginal language were less likely to have completed high school than those who did not speak an Aboriginal language. This was true for both First Nations adults who were and were not taught the language in school, although on-reserve FN adults who had been taught the language in school were more likely to have completed high school than those adults who had not learned the language in school. However, of adults who had graduated from high school, those who spoke an Aboriginal language were no less likely to have completed post-secondary levels of schooling than adults who did not speak an Aboriginal language.

For First Nations adults living off reserve, those who spoke an Aboriginal language but were not taught the language in school were less likely to have completed high school, as compared to those who did not speak an Aboriginal language. However, similar to Inuit adults and First Nations adults living on selected reserves, if they had graduated high school, speaking an Aboriginal language was not negatively associated with completing post-secondary school compared to those not speaking an Aboriginal language.

\section{Discussion}

One of the intriguing findings of the current study is that even after controlling for child and family factors, speaking an Aboriginal language was associated with positive school outcomes for young children. As well, for adults who had completed high school, those who spoke an Aboriginal language were no less likely to have completed post-secondary levels of schooling than adults who did not speak an Aboriginal language. To our knowledge, this study is the first to report positive associations of speaking an Aboriginal language with school outcomes using population-based data.

This study also demonstrates that there is much variability among Aboriginal groups of children and adults who speak an Aboriginal language. Aboriginal language was most frequently spoken by Inuit and less so by First Nations peoples, particularly those living off reserve. This finding was consistent for both children and adults. Moreover, the majority of Inuit adults who spoke an Aboriginal language reported having it as their first language and using it both at home and at work more frequently than First Nations peoples. Furthermore, fewer children than adults living on selected First Nations reserves spoke an Aboriginal language, consistent with data from the Census of Canada (Statistics Canada 2009) suggesting a decline in the 
Table 4. Odds ratios and confidence intervals predicting adult outcomes.

\begin{tabular}{|c|c|c|c|c|c|c|c|}
\hline \multirow[b]{2}{*}{ Outcome } & & \multicolumn{2}{|r|}{ Inuit } & \multicolumn{2}{|c|}{$\begin{array}{l}\text { First Nations on } \\
\text { selected reserves }\end{array}$} & \multicolumn{2}{|c|}{$\begin{array}{l}\text { First Nations off } \\
\text { reserve }\end{array}$} \\
\hline & & OR & $95 \% \mathrm{CI}$ & OR & $95 \% \mathrm{CI}$ & OR & $95 \% \mathrm{CI}$ \\
\hline \multirow[t]{4}{*}{ Completed high school (including GED) } & $\begin{array}{l}\text { Does not speak an Aboriginal Language } \\
\text { Speaks an Aboriginal Language }\end{array}$ & 1.00 & & 1.00 & & 1.00 & \\
\hline & Schoolteachers do not help & 0.21 & $(0.10-0.44)$ & 0.64 & $(0.53-0.76)$ & 0.66 & $(0.48-0.89)$ \\
\hline & Schoolteachers help & 0.21 & $(0.12-0.37)$ & 0.82 & $(0.69-0.97)$ & 0.77 & $(0.57-1.05)$ \\
\hline & $N$ & 1846 & & 4976 & & 5421 & \\
\hline \multirow[t]{4}{*}{ Completed PSE } & Does not speak an Aboriginal Language & 1.00 & & 1.00 & & 1.00 & \\
\hline & $\begin{array}{l}\text { Speaks an Aboriginal Language } \\
\text { Schoolteachers do not help }\end{array}$ & 157 & $(0.52-4.70)$ & 1.11 & $(0.78-1.59)$ & 0.70 & $(0.43-1.13)$ \\
\hline & Schoolteachers help & 0.92 & $(0.45-1.88)$ & 1.02 & $(0.77-1.37)$ & 0.77 & $(0.39-1.52)$ \\
\hline & $N$ & 498 & & 2075 & & 2870 & \\
\hline
\end{tabular}

Source: 2001 Aboriginal Peoples Survey.

Results significant at $p<0.05 \%$ are in bold. All models control for age, gender, health status, income, and number of people in the household. Models for First

Nations also control for living in an urban or rural area. 
use of Aboriginal languages for First Nations people, yet as we have described, these groups are served by different schools.

For all Aboriginal groups considered in this study, the importance that parents placed on learning an Aboriginal language was consistently related to the child's knowledge of an Aboriginal language and not surprisingly, parents were most often the ones who helped teach the language to their children. Other factors related to knowledge of an Aboriginal language included household income. Increased household income was related to children's knowledge of an Aboriginal language for First Nations children on selected reserves. However, low income was related to children's knowledge of an Aboriginal language for First Nations children living off reserve. Moreover, the pattern of results was similar for adults. This pattern could suggest differences in the on- and off-reserve environments contributing to knowledge of Aboriginal language as well as the value of knowledge of an Aboriginal language in these different contexts. It may also reflect other cultural and community differences. Unfortunately these were not specifically examined in the current study and warrant replication and further exploration. Furthermore, there was no interaction of income and Aboriginal language on educational outcomes, suggesting that the association of learning an Aboriginal language with school outcomes was the same across all income groups.

For Inuit children, those who spoke and were helped to learn an Aboriginal language in school were more likely to be doing well in school compared to Inuit children who did not speak an Aboriginal language. Those who spoke an Aboriginal language but did not have help in school were also more likely to do well and look forward to going to school but this difference was not statistically significant. This may suggest that for Inuit children, speaking an Aboriginal language is the most important feature, although the Inuit are also most likely of all the three groups to speak an Aboriginal language (63\% of children, $73 \%$ of adults) to be taught by parents $(87 \%)$ and to have help with it at school $(67 \%)$. Similarly, First Nations children living on selected reserves who spoke an Aboriginal language (learned in or out of school) were more likely to be rated as doing well in school compared to First Nations children who did not speak an Aboriginal language. A trend did exist for First Nations children, both on and off reserve who were helped to learn the language at school to look forward to going to school (although this effect did not reach statistical significance). However, for First Nations children both on selected reserves and off reserve, and those children who spoke an Aboriginal language but did not have help with the language from their schoolteachers were less likely to look forward to going to school. These effects were over and above the effects of gender, age, health status, household income, number of people living in the household, and living in an urban or rural area. These results may suggest positive and possibly protective effects of speaking an Aboriginal language on school outcomes and the importance of the supportive environment where teachers help children learn an Aboriginal language in the school setting.

An interesting pattern of results, although not significant, warrants discussion. Inuit children who spoke an Aboriginal language (those helped by teachers in school and not) were less likely to be expelled or suspended from school. Whereas First Nations children living off reserve who spoke an Aboriginal language (regardless of being helped at school) were more likely to be suspended or expelled. These associations occurred over and above family socio-demographic factors. Possible explanations may include differences in living environments for Inuit children 
surrounded by other Aboriginal speakers versus First Nations children living off reserve who may be exposed only to few Aboriginal speakers in their communities. In addition, Inuit and First Nations children on and off reserve are served by different school boards that may also have a different impact on their outcomes.

The association of knowledge of an Aboriginal language with school outcomes differed for the adult cohort in this study. Adults who spoke an Aboriginal language were less likely to have completed high school than those who did not speak an Aboriginal language, whether they were taught the language in school or not. The high school graduation rates for adults who spoke an Aboriginal language were significantly lower than the rates for adults who did not speak an Aboriginal language and this pattern was consistent for Inuit as well as First Nations adults living both on and off reserves. This result appears inconsistent with the finding that young children who spoke an Aboriginal language were rated as doing better in school. One possible explanation is that differences could exist between the cohorts of children and adults in the sample and speaking an Aboriginal language could have different benefits for the child and adult cohorts.

One possibility is that children who speak an Aboriginal language do well in elementary school and then experience a shift in outcomes upon entering high school. Bougie, Wright, and Taylor (2003) showed that as children shift from being taught solely in an Aboriginal language to being taught solely in English or French, they experience a decrease in self-esteem. It is possible that when children who speak an Aboriginal language enter high school they experience more difficulties and disengagement from school than children who do not speak an Aboriginal language, possibly because children who do not speak an Aboriginal language likely speak English or French and may already be acclimated to non-Aboriginal languages and culture. In addition, if the switch to English or French as a language of instruction occurs before the child has acquired a strong foundation in their native Aboriginal language, negative effects on self-esteem and language and school outcomes may be observed, which may then set the stage for future negative outcomes such as high school dropout. Another possibility particularly for Aboriginal children living on reserve or small and remote communities is that they frequently attend high school outside of their community. One way to investigate how Aboriginal children's school experiences affect them as they age is to study a group of children over time, for example following a cohort of Aboriginal children from childhood to adulthood to observe if a shift in educational outcomes occurs at a certain point for children who speak an Aboriginal language and also to investigate the processes and factors that may be associated with such changes. Unfortunately, to our knowledge, data in this area is lacking.

Furthermore, it is possible that the relationship between language and educational outcomes varies by geographic region. For example, young Inuit adults who do not speak an Aboriginal language may be more likely to live in Southern urban centres than in northern Inuit communities. Differences in later educational opportunities, as well as the differential opportunities associated with higher levels of education in terms of employment could be due to differences between these two areas. Geographic differences are also associated with educational outcomes and educational funding variability that differ by province (Canadian Council on Learning 2007), which could lead to geographic differences in Aboriginal peoples school outcomes. Unfortunately, the sample size was not large enough to examine 
the relationship between language and educational outcomes by geographical region in the present study.

Although the large population-based data source is a strength of the current study, the limitations of the existing survey data need to be discussed. While the APS asks about whether or not a student was helped to learn an Aboriginal language in school, it is not known the extent to which the Aboriginal language was used or taught in school. It is possible that more or less time spent in formal language instruction or the amount of time spent learning an Aboriginal language could have different effects on educational outcomes. As we have discussed, continuity and discontinuity in Aboriginal language instruction over time and in various school contexts may also be important. Moreover, children taught an Aboriginal language by an Aboriginal teacher may share cultural values and experiences with the teacher, further enhancing the educational process but also providing more appropriate learning experiences, tools, and assessments resulting in better academic outcomes. The wording of the language instruction items were not worded in a similar way for the child and adult questionnaires. For example, the child survey asked if 'schoolteachers helped the child learn the language', possibly implying direct instructions. The adult survey asked if any of the teachers taught them in an Aboriginal language, whereas Aboriginal language was the medium of instruction. The differences in wording leave open the possibility that different criteria determined answers and that these two constructs are not necessarily identical for children and for adults in this study.

In addition, although all of the children's outcomes were parent-reported, the positive impact of knowledge of an Aboriginal language had the largest impact on certain outcomes. The most positive impacts were observed for the outcomes that may be considered the most subjective (doing well in school, looking forward to going to school). However, positive finding presented in the area of achievement and motivation has been reported by others (Kirkness and Sheena 1992) and inherent biases based on parent reports, if present, would not have differentially influenced one group compared to another. Arguably, grade repetition and school suspension or expulsion are more 'objective' outcomes (although parent-reported in the present study), and while the direction of effects was similar, significant differences between children who did and did not speak an Aboriginal language did not emerge. As we have shown, knowledge of an Aboriginal language was related to parents valuing the importance of speaking an Aboriginal language. Thus, this association may be based on parents' perceptions. In contrast, the adult outcomes, although also self-reported, were based only on the more 'objective' outcome of high school and post-secondary completion, and perhaps less amenable to subjective interpretations. This could be another reason for the difference in outcomes between children and adults in this study. Additional outcome measures such as direct measures, standardised tests, teacher reports and/or administrative data may be more 'objective' measures of how Aboriginal language knowledge influences school outcomes, yet often the cultural relevance of such measures is questionable (Greenfield 1997). Lastly, this study uses cross-sectional data from one point in time. While several time points of crosssectional data would be informative, following children longitudinally and acquiring both quantitative data on outcomes as well as qualitative data on education experiences would greatly enhance our understanding of how Aboriginal language ability influences both children's and adult's educational outcomes. 


\section{Limitations and future studies}

Several limitations have been discussed including the cross-sectional nature of the study, differences in wording for the child and adult questionnaires, the lack of information on the extent and quality of Aboriginal language instruction, training of instructors, the parent-reported outcomes, and the lack of sufficient sample to look at regional and other differences (for example, the subgroup of those whose first language was an Aboriginal one yet do not speak an Aboriginal language). Future research could examine whether the quality, timing, or amount of language instruction makes a difference for academic outcomes.

\section{Conclusion}

This study has implications for educators, school boards, policy-makers, and researchers interested in the education of Aboriginal children and youth. Although the knowledge and use of Aboriginal languages is declining, particularly for children, this study demonstrates that parental influence is important and that being taught in an Aboriginal language may have positive school outcomes for children who speak an Aboriginal language. Implications include the need for additional quantitative as well as qualitative data in this area to gain a better understanding of the processes involved as well as longitudinal data to examine effects and changes over time.

\section{Notes}

1. Caution should be exercised in generalising the characteristics of the reserves that participated in APS to the entire on-reserve population in Canada. The sample selection of reserve communities for APS was not designed to be representative of the entire onreserve population. There was no randomness in the selection process of the reserves and no randomness in the reserves that refused to participate. As a result, any aggregation of APS reserve data is only representative of the reserves that participated in APS, and cannot be considered representative of the total on-reserve population. However, the data is representative at the community level for each reserve community that was selected and participated in APS. The sampling strategy for APS that focused on the large reserve communities covered $44 \%$ of the entire on-reserve population. In an attempt to evaluate how comparable the data collected on the APS-selected reserves are to the entire onreserve population, a small study was carried out. Socio-economic characteristics of reserves that participated in the 2001 APS were compared to the same characteristics of the total reserve population from the 2001 Census. The variables used in the comparison were as follows: sex, age (five-year age groups), highest level of schooling, labour force activity, mobility status (one year), mother tongue, and housing. While the differences in distributions were relatively small for most of the characteristics measured with the exception of the mother tongue variable, this does not mean that differences would not be observed for other characteristics. Equally, it does not cover all characteristics measured in APS - such as information about Aboriginal culture and health.

2. For First Nations both on and off reserve, there was no difference in outcomes for adults who responded yes to only one or to both questions. For Inuit, the sample size for respondents who answered yes to only one of the questions was too small to assess whether there was a difference in outcomes for adults who responded yes to one or both questions.

3. While Canadian schools generally limit the practice of holding a child back a grade, this practice exists, although no official policy is documented and the number of students held back is not tracked (Westbury 1994).

4. The survey sample was designed to be nationally representative. However, due to factors such as sample design, non-response and discrepancies between the characteristics of the 
sample and known totals for the target population (post-stratification), the data was weighted to correct for biases that may have ensued due to the different patterns by respondents (see Statistics Canada 2003b for details).

\section{References}

Assembly of First Nations. 1990. Towards linguistic justice for First Nations. Ottawa, ON: Assembly of First Nations.

Ball, J. 2007. Aboriginal young children's language and literacy development: Research evaluating progress, promising practices, and needs. Ottawa, ON: Canadian Language and Literacy Networked Centre of Excellence.

Bell, D., K. Anderson, T. Fortin, J. Ottmann, S. Rose, L. Simard, and K. Spencer. 2004. Sharing our success: Ten case studies in Aboriginal schooling. Kelowna, BC: Society for the Advancement of Excellence in Education.

Bougie, Évelyne. 2009. Aboriginal Peoples Survey, 2006: School experiences of off-reserve First Nations children aged 6 to 14. Ottawa, ON: Ministry of Public Works and Government Services.

Bougie, Évelyne, Heather Tait, and Elisabeth Cloutier. 2010. Aboriginal language indicators for off-reserve First Nations children under the age of six in Canada (Statistics Canada, catalogue no. 89-643-X). Ottawa, ON: Ministry of Public Works and Government Services.

Bougie, Évelyne, Stephen C. Wright, and Donald M. Taylor. 2003. Early heritage-language education and the abrupt shift to a dominant-language classroom: Impact on the personal and collective esteem of Inuit children in Arctic Québec. International Journal of Bilingual Education and Bilingualism 6: 349-73.

British Columbia Ministry of Education. 2010. Aboriginal report 2004/05-2008/09: How are we doing? Victoria, BC: British Columbia Ministry of Education.

Burnaby, Barbara. 2008. Language policy and political issues in education. In Encyclopedia of language and education, ed. S. May and N.H. Hornberger, 331-41. New York: Springer Science and Business Media.

Burnaby, Barbara and Roderic Beaujot. 1986. The use of Aboriginal languages in Canada: An analysis of 1981 census data. Prepared for the Social Trends Analysis Directorate and Native Citizens Directorate. Ottawa, ON: Department of the Secretary of State.

Canadian Council on Learning. 2007. The state of learning in Canada. Ottawa, ON: Author.

Canadian Council on Learning. 2008. Important literacy levels among Aboriginal Canadians. Ottawa, ON: Author.

Cree School Board. 2008. Cree school board educational review: 2007-08. Mistissini, QC: Author.

Feurer, Hanny. 1993. Beyond multilingual education: The Cree of Waskaganish. The Canadian Journal of Native Education 20, no. 1: 87-95.

First Nations Schools Association. 2010. Sixth annual school measures and data collection project 2009/10: Final report. Vancouver, BC: Author.

Fulford, George, Jackie Moore Daigle, Blair Stevenson, and Tracey Wade. 2007. Sharing our success: More case studies in Aboriginal schooling. Kelowna, BC: Society for the Advancement of Excellence in Education.

Government of Canada. 2002. The Canada we want: Speech from the Throne to open the Second Session of the Thirty-Seventh Parliament of Canada - September 30, 2002. Ottawa, ON: Government of Canada, Governor General.

Government of Canada. 2010. Speech from the Throne: Frequently asked questions. Ottawa, ON: Author. http://www.sft-ddt.gc.ca/eng/media.asp?id=1367 (accessed April 12, 2011).

Greenfield, Patricia M. 1997. You can't take it with you: Why ability assessments don't cross cultures. American Psychologist Association 52: 1115-24.

Harrison, Barbara. 1998. Te Wharekura o rakaumangamanga: The development of an Indigenous language immersion school. Bilingual Research Journal: The Journal of the National Association for Bilingual Education 22: 297-316.

Hawthorn, H.B., M.A. Tremblay, F.G. Vallee, and J. Ryan. 1967. A survey of the contemporary Indians of Canada: Economic, political, educational needs and policies (Volume II). Ottawa, $\mathrm{ON}$ : Indian Affairs Branch. 
Kativik School Board. 2010. History of education in Nunavik. St. Laurent, QC: Kativik School Board. http://www.kativik.qc.ca/en/history-of-education-in-nunavik (accessed April 12, 2011).

Kirkness, Verna, and J. Bowman Sheena. 1992. First Nations and schools: Triumphs and struggles. Toronto, ON: Canadian Education Association.

Louis, Winnifred, and Donald M. Taylor. 2001. When the survival of a language is at stake: The future of Inuttitut in arctic Québec. Journal of Language and Social Psychology 20: 111-43.

Manitoba Education, Citizenship and Youth. 2007a. Aboriginal education action plan: March 2007 highlights report. Winnipeg, MB: Author.

Manitoba Education, Citizenship and Youth. 2007b. Kindergarten to grade 12 Aboriginal languages and cultures: Manitoba curriculum framework of outcomes. Winnipeg, MB: Author.

Ministry of Education. 2008. Nga Haeata Matauranga: Annual report on Maori education 2007/08. Wellington, NZ: Author.

Norris, Mary Jane. 1998. Canada's Aboriginal languages. Canadian Social Trends 51: 8-16.

Norris, Mary Jane. 2007. Aboriginal languages in Canada: Emerging trends and perspectives on second language acquisition (Statistics Canada, catalogue no. 11-008). Ottawa, ON: Minister of Public Works and Government Services.

Phillips, Susan, and Helen Raham. 2008. Sharing our success. Paper presented at Sharing our Success: Promising practices in Aboriginal education, national research and policy conference convened by the Society for the Advancement of Excellence in Education (SAEE), November 23-27, 2007, at the University of Winnipeg, Winnipeg.

Rao, J.N.K., C.F.J. Wu, and K. Yue. 1992. Some recent work on resampling methods for complex surveys. Survey Methodology 18, 209-17 (Statistics Canada, catalogue 12-000). Ottawa, ON: Minister of Public Works and Government Services.

Romero-Little, Mary Eunice, and Teresa L. McCarty. 2006. Language planning challenges and prospects in Native American communities and schools. Tempe, AZ: Education Policy Studies Laboratory: Language Policy Research Unit.

Royal Commission on Aboriginal Peoples. 1996. Report of the royal commission on Aboriginal peoples: Perspectives and realities, vol. 4. Ottawa, ON: Minister of Supply and Services Canada.

Rust, K.F., and J.N.K. Rao. 1996. Variance estimation for complex surveys using replication techniques. Statistical Methods in Medical Research 5: 281-310.

Saskatchewan Education, Training and Employment. 2003. Indian and Métis education policy from kindergarten to grade 12. Regina, SK: Saskatchewan Education, Training and Employment.

Statistics Canada. 1998. 1996 Census: Aboriginal Data (Statistics Canada, catalogue 11-001E). Ottawa, ON: Minister of Public Works and Government Services.

Statistics Canada. 2003a. Aboriginal peoples survey 2001, initial findings: Wellbeing of the non reserve Aboriginal population. Ottawa, ON: Minister of Public Works and Government Services.

Statistics Canada. 2003b. Aboriginal peoples survey 2001: Concepts and methods guide. Ottawa, ON: Minister of Public Works and Government Services.

Statistics Canada. 2009. Aboriginal Peoples in Canada in 2006: Inuit, Métis, and First Nations, 2006 Census. Ottawa, ON: Minister of Public Works and Government Services.

Stiles, Dawn B. 1997. Four successful indigenous language programs. In Teaching indigenous languages, ed. J. Reyhner, 148-262. Flagstaff, AZ: Northern Arizona University.

Tait, Heather, Elisabeth Cloutier, and Évelyne Bougie. 2010. Inuit language indicators for Inuit children under the age of six in Canada (Statistics Canada, catalogue no. 89-643-X). Ottawa, ON: Minister of Public Works and Government Services.

Task Force on Aboriginal Languages and Cultures. 2005. Towards a new beginning: A foundation report for a strategy to revitalize First Nations, Inuit and Métis language and cultures. Ottawa, ON: Department of Canadian Heritage.

Thomas, Eleanor. 2009. Canadian nine-year-olds at school. Ottawa, ON: Minister of Public Works and Government Services.

Westbury, M. 1994. The effect of elementary grade retention on subsequent school achievement and ability. Canadian Journal of Education 19, no. 3: 241-50. 
Wright, Stephen C. and Donald M. Taylor. 1995. Identity and the language of the classroom: Investigating the impact of heritage versus second language instruction on personal and collective self-esteem. Journal of Educational Psychology 87, no. 2: 241-52.

Wright, Stephen C., Donald M. Taylor, and Judy Macarthur. 2000. Subtractive bilingualism and the survival of the Inuit language: Heritage- versus second-language education. Journal of Educational Psychology 92, no. 1: 63-84.

\title{
Appendix 1. Communities taking part in the APS.
}

Following is a list of communities selected for the 2001 Aboriginal Peoples Survey (APS).

\section{(a) First Nations Communities}

\author{
Newfoundland and Labrador \\ Samiajij Miawpukek \\ Prince Edward Island \\ Lennox Island 1 \\ Nova Scotia \\ Eskasoni 3 \\ Indian Brook 14 \\ Millbrook 27 \\ New Brunswick \\ Burnt Church 14 \\ Devon 30 \\ Quebec \\ Eastmain \\ Mistissini \\ Nemiscau \\ Oujé-Bougoumou \\ Waskaganish \\ Waswanipi \\ Wemindji \\ Whapmagoostui
}

\section{Ontario}

Christian Island 30 and 30A

Couchiching 16A

Curve Lake First Nation 35

Deer Lake

English River 21

Fort Hope 64

Fort William 52

Garden River 14

Kettle Point 44

Lac Seul 28

Mississagi River 8

Mnjikaning First Nation 32 (Rama First Nation 32)

Pikwakanagan (Golden Lake 39)

Sagamok

Sandy Lake 88

Wikwemikong Unceded 26

\section{Manitoba}

Chemawawin 2

Cross Lake 19, 19A and 19E

Ebb and Flow 52

Fairford 50

Fisher River 44 and $44 \mathrm{~A}$

Nelson House 170

Norway House 17 
Opaskwayak Cree Nation 21A, 21B, 21E, 21I

Oxford House 24

Peguis 1B

Sandy Bay 5

Sioux Valley 58

Split Lake 171

St. Theresa Point

Waywayseecappo First Nation

\section{Saskatchewan}

Ahtahkakoop 104

Assiniboine 76

Big River 118

Buffalo River Dene Nation 193 (Peter Pond Lake 193)

Canoe Lake 165

Chicken 224 and 225

Clearwater River

Cote 64

Cowessess 73

Flying Dust First Nation 105 (Meadow Lake 105)

Gordon 86

James Smith 100

Kitsakie 156B

Lac La Ronge 156

Little Pine 116

Makaoo (Part) 120

Makwa Lake 129B and 129C

Ministikwan 161 and 161A

Montreal Lake 106 and 106B

Moosomin 112B

Mosquito 109

Peepeekisis 81

Piapot 75

Poundmaker 114

Seekaskootch 119

Standing Buffalo 78

Sturgeon Lake 101

Wapachewunak 192D

Waterhen 130

White Bear 70

Alberta

Alexis 133

Blood 148

John d'Or Prairie 215

Louis Bull 138B

Montana 139

Peigan 147

Samson 137

Siksika 146

Stoney 142, 143, 144

Stony Plain 135

Tsuu T'ina Nation 145 (Sarcee 145)

Utikoomak Lake 155 and 155A

Wabamun 133A

Wabasca 166, 166A, 166B, 166C, 166D)

White Fish Lake 128

\section{British Columbia}

Alert Bay 1 and 1A 
Alkali Lake 1

Campbell River 11

Capilano 5

Chehalis 5

Chemainus 13

Cole Bay 3

Cowichan 1

East Moberly Lake 169

Fort Nelson 2

Gitanmaax 1

Gitsegukla 1

Gitwangak 1

Hagwilget 1

Kamloops 1

Kitamaat 2

Mission 1

Musqueam 2

Nanaimo Town 1

Nishga Nation (New Aiyansh, Laxgalts'ap, Gitwinksihlkw, Gingolx)

Okanagan (Part) 1 CSD-801, (Part) 1 CSD-804

Seabird Island

Sechelt (Part) CSD-803

South Saanich 1

Stony Creek 1

Tache 1

Tsahaheh 1

Tsinstikeptum 9

Tsulquate 4

Williams Lake 1

Woyenne 27

Northwest Territories

Hay River Dene 1

(b) Communities with large Inuit populations

Newfoundland and Labrador

Happy Valley-Goose Bay

Makkovik

Nain

Postville

Rigolet

Nunavik (northern Quebec)

Akulivik

Aupaluk

Chisasibi

Inukjuak

Ivujivik

Kangiqsualujjuaq

Kangiqsujuaq

Kangirsuk

Kuujjuaq

Kuujjuarapik

Puvirnituq

Quaqtaq

Salluit

Tasiujaq

Umiujaq 


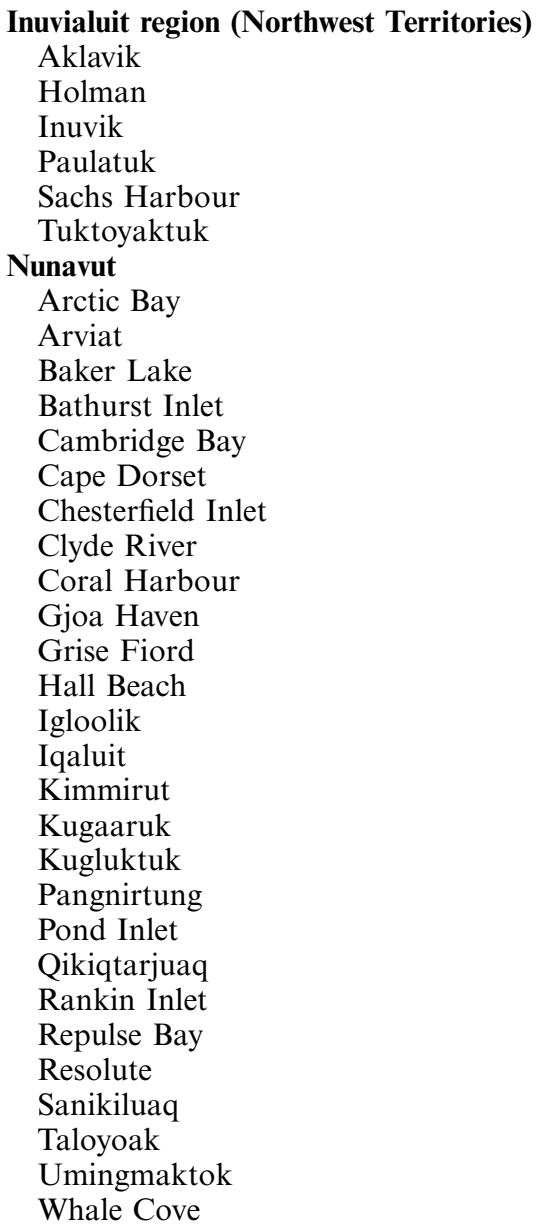

(c) Communities with large Métis populations

Newfoundland and Labrador

Port Hope Simpson

Manitoba

Alonsa

Camperville

Cormorant

Duck Bay

Moose Lake

Mountain (North)

Norway House

St. Laurent

Wabowden

Saskatchewan

Beauval

Buffalo Narrows

Green Lake

Île-à-la-Crosse

La Loche

North Battleford 
Pinehouse

Prince Albert

Alberta

Buffalo Lake

East Prairie

Elizabeth

Fishing Lake

Fort Vermilion

Gift Lake

Grouard Mission

Kikino

Paddle Prairie

Peavine

Wabasca

Wood Buffalo

Yukon

Whitehorse

Northwest Territories

Déline

Fort Good Hope

Fort Liard

Fort McPherson

Fort Providence

Fort Resolution

Fort Simpson

Fort Smith

Rae-Edzo

Tulita

Wha Ti

Yellowknife 